International Conference on Renewable Energies and Power Quality (ICREPQ'11)

Las Palmas de Gran Canaria (Spain), 13th to 15th April, 2011

\title{
Advances in phase change materials for thermal solar power plants Quality
}

\author{
I. Fernández ${ }^{1}$, C.J. Renedo ${ }^{1}$, S. Pérez ${ }^{1}$, J. Carcedo $^{1}$ and M. Mañana ${ }^{1}$ \\ ${ }^{1}$ Department of Electric and Energy Engineering \\ E.T.S.I.I.T., Cantabria University \\ 39005 Santander (Spain) \\ Phone/Fax number:+0034 942200932, e-mail: fernandei@unican.es, renedoc@unican.es, perezrs@unican.es, \\ carcedoj@unican.es, mananam@unican.es
}

\begin{abstract}
Thermal solar energy offers a huge opportunity to reduce fuel dependency and environmental impact created by fossil fuel consumption. One of the main disadvantages of this renewable energy is its intermittence which decreases thermal solar power plants performance. In order to reduce cost electricity is necessary to create thermal solar plants which include thermal storage. There are different options of thermal storage: sensible, latent and chemical heat. It has been demonstrated that latent heat could store large amount of energy per unit mass. Moreover, latent heat storage could store fusion heat at a constant temperature which is the phase transition temperature of the phase change materials (PCM). However, these materials have a critical limitation that needs to be resolved in order to reduce operation cost of solar plants. This limitation is their low heat conductivity. This paper gathers the main solutions that are being analyzed in order to increase the possibilities to use $\mathrm{PCMs}$ in a high temperature thermal storage that is essential to develop optimum thermal solar power plants.
\end{abstract}

\section{Key words}

Phase change materials, thermal conductivity, thermal solar power plants

\section{Introduction}

Reducing worldwide fuel dependency and environmental impact requires the development of renewable energies such as wind, hydropower biomass or solar. Thermal solar power plants represent a huge opportunity in areas where solar irradiation is of at least $2,000 \mathrm{kWh} / \mathrm{m}^{2} /$ year [1]. However, this technology has a critical limitation which is its intermittence. This inhibits the regular electricity generation that decreases plant performance. For this reason, it is essential the development of an economical and effective energy storage system to reduce electricity cost.

In solar thermal generation, thermal storage is the suitable storage mode. There are three methods to storage thermal energy: sensible, latent and chemical heat. Latent heat storage systems have the potential of storing a large amount of energy per unit mass. Moreover, latent heat storage could store fusion heat at a constant temperature which is the phase transition temperature of the phase change materials (PCMs). Unfortunately, most of the PCMs possess a low thermal conductivity (around $1 \mathrm{~W} / \mathrm{mK}$ ) which limits their deployment in large scale applications like thermal solar power plants [2]. This is the reason that has enhanced the development of different solutions whose target is improving the heat transfer from PCMs. This work collects the main solutions that are being developed to make possible the implementation of PCMs in real solar power plants.

\section{Thermal storage}

A solar thermal power plant could have four elements: solar field, heat transfer fluid (HTF), thermal storage system and finally power generation system (Fig. 1). The thermal storage system allows use the excess of energy at night and/or cloudy days to increase plant performance. In sensible heat storage, the temperature of the storage material varies with the amount of energy stored. The amount of thermal energy that is stored depends on its specific heat and on the temperature variation. It has been implemented in thermal solar power plants through thermocline or two tanks systems using molten salt as storage medium [2].

Latent heat thermal energy storage is attractive due to its high energy storage density. When compared to conventional sensible heat energy storage systems, latent heat energy storage system requires a smaller weight and volume of material for a given amount of energy [3]. Furthermore, latent heat storage stores fusion heat at a constant or near constant temperature which correspond to the phase transition temperature of the PCMs. In practice, solid-liquid phase change is preferred because of simultaneous slight volume variation and high enthalpy variation.

The last approach for thermal storage is based on thermochemical reactions. This storage method could allow long-term storage but its technical complexity and 
high costs is not easily compatible with cost-effective solar electricity production.

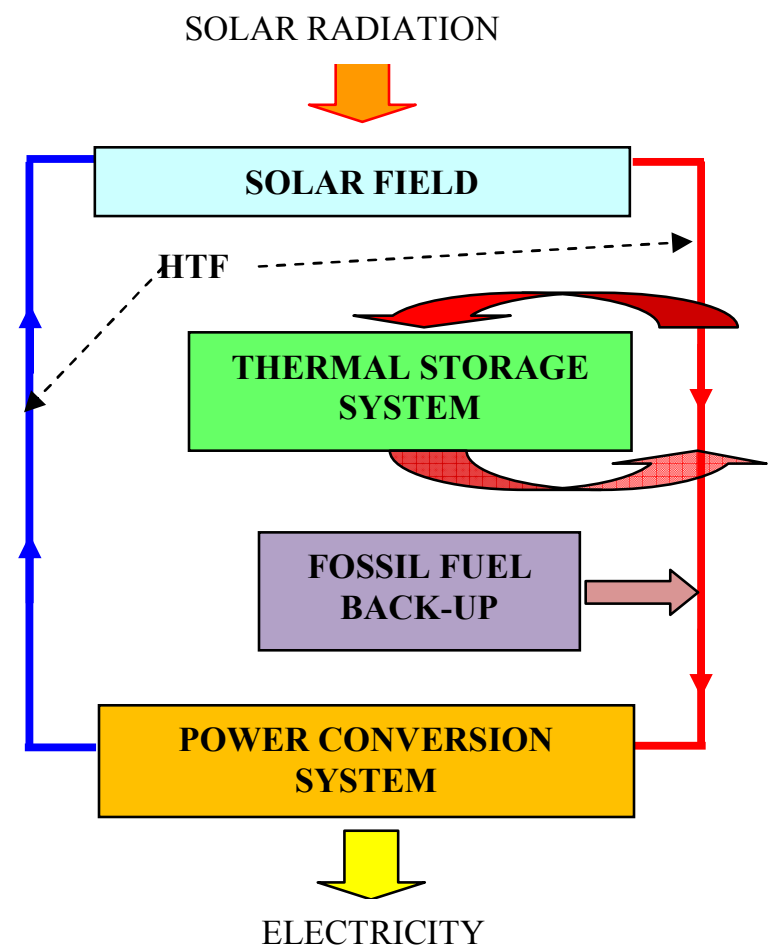

Fig. 1. Diagram of a thermal solar power plant [9].

\section{Phase change materials}

Latent heat storage through PCMs has the advantage of compactness because the fusion heat of PCMs is quite larger than their specific heats. The PCMs could be classified into two groups: organic and inorganic compounds. Inorganic compounds show a volumetric latent thermal energy storage capacity trice that of organic compounds. Nevertheless, organic substances present advantages such as their ability to melt congruently, their self-nucleation and their non-corrosive behaviour [4].

A PCM needs to have a set of characteristics to be selected as storage medium [3]:

- Melting point in the desired operating temperature range.

- High fusion latent heat per unit mass.

- High specific heat.

- High thermal conductivity.

- Small volume changes during phase transition.

- Little or no subcooling during freezing.

- Chemical stability.

- Contain non-poisonous, non-flammable and nonexplosive elements/compounds.

- Available in large quantities at low cost.

Although latent heat thermal energy storage offers a huge opportunity due to its heat storage density and there are a huge variety of PCMs whose melting point is suitable for large scale solar thermal electricity plants [5], the PCMs has not been up to the expected level and the large-scale utilization in latent heat thermal storage (LHTS) [6]. This is because most of PCMs have a low thermal conductivity (around $1 \mathrm{~W} / \mathrm{mK}$ ), which prolong the charging and discharging period.

Michels and Pitz-Paal used a cascade of multiple phase change materials (PCM) to try increase the efficiency of the thermal storage system used in a solar plant [7]. Three PCMs were selected for experimental investigations: sodium nitrate $\left(\mathrm{NaNO}_{3}\right)$, an eutectic mixture of potassium nitrate and potassium chloride $\left(\mathrm{KNO}_{3} / \mathrm{KCl}\right)$ and potassium nitrate $\left(\mathrm{KNO}_{3}\right)$. The experiments were conducted with vertical shell and tube type heat exchanger devices under realistic operation parameters. Even though they got increase the efficiency of the thermal storage system the PCM's heat conductivity went on being too low. For this reason, it is crucial the design and development of proper heat transfer enhancement techniques to compensate the low thermal conductivity to design cost-effective LHTS.

In past decades, several methods have been suggested to enhance heat transfer in low temperature LHTS systems in which the PCM is paraffin [8]. However, until recent years few works have focused on high temperature LHTS, that are the systems required in solar power plants.

\section{Thermal conductivity enhancement of PCMs}

This section describes the main approaches that are being studied to increase thermal conductivity of PCMs for high temperature LHTS.

One of these approaches is the development of a reflux heat transfer storage system (RHTS) for producing hightemperature superheated steam in the temperature range $350-400^{\circ} \mathrm{C}$ (Fig. 2). In this approach, the HTF is used to transfer heat between the thermal storage medium (PCM) and two heat exchangers (HE) placed externally of the PCM at the bottom and the top. The top HE, is fed with high pressure water to produce super-heated steam during the storage discharge cycle. The bottom HE is used to charge the thermal storage. It is immersed in the liquid HTF and connected to the solar working fluid. During heat charge cycles, due to pool-boiling of the HTF, there is an intensive flow of vapours up through the transport channels distributed in the PCM. By condensation on the channels' surfaces, the latent energy of vapours is transferred across the walls to the PCM. On discharge, the heat flow direction is reversed. The hot PCM causes the evaporation of liquid HTF and the vapours transmit heat to the top through condensation.

The thermal storage medium used in this system was a Zinc-Tin alloy, which serves as PCM. The hightemperature HTF added to the storage medium in order to enhance heat exchange within the storage system is a eutectic mixture of $26.5 \%$ biphenyl and $73.5 \%$ diphenyl oxide.

It was shown that a PCM with a fraction of $70 \mathrm{wt} . \% \mathrm{Zn}$ in the alloy $\left(\mathrm{Zn}_{70} \mathrm{Sn}_{30}\right)$ is optimal to improve charging and discharging process [9].

Shabgard et al. incorporated heat pipes (HPs) to serve as thermal conduits between the HTF from solar collectors and the PCM [10]. The HPs can transfer heat between the HTF and the PCM with evaporation and condensation of 
the HPs working fluid occurring at the ends of the HPs. These authors developed a thermal network model to investigate the effect of adding HPs to a high temperature latent heat storage system. They considered charging (PCM melting) and discharging (PCM solidification) in two storage configurations, one with the PCM contained within tubes over which the heat transfer fluid flows (Fig. $3 \mathrm{a}$ ), and the second with the PCM surrounding tubes that conveys the heat transfer fluid (Fig. 3b). The influence of the number of HPs as well as their orientation relative to the HTF flow direction and the gravity vector was also investigated.

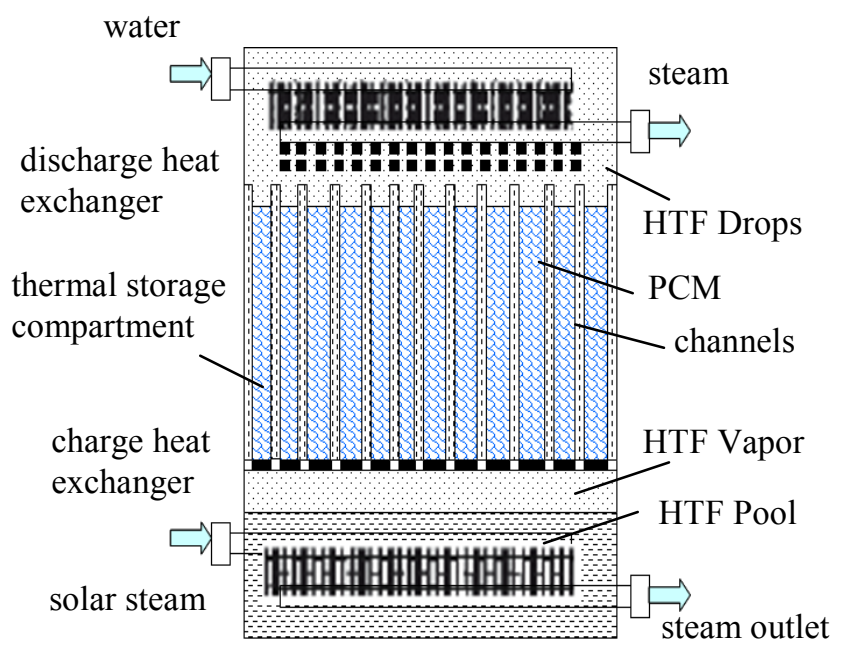

Fig. 2. Diagram of the RHTS concept [9].
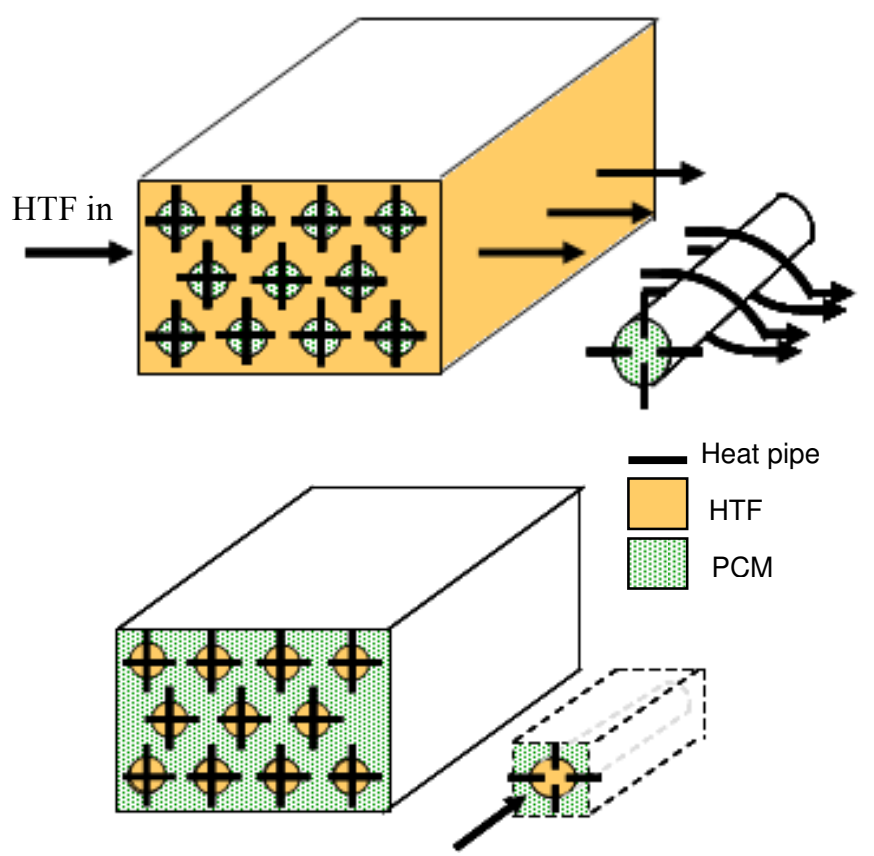

HTF flow

Fig. 3. Two LHTES units: (a) the PCM surrounds the HTF tubes, (b) the HTF passes over tubes containing PCM [10].

Guo and Zhang using the Fluent version 6.2 studied numerically the heat transfer enhancement of the discharging process [8]. They wanted to demonstrate how the obtained information could be used to design a new type of LHTS. They proposed a new type of LHTS structure using aluminium foils to improve the heat transfer. They selected the eutectic system $\mathrm{KNO}_{3}-\mathrm{NaNO}_{3}$ as the PCM. Aluminium foils were arranged orthogonal to the axis of the steam tubes and $\mathrm{KNO}_{3}-\mathrm{NaNO}_{3}$ as the PCM fills the spaces between the foils and tubes, while water/steam flows inside the tubes. The tubes were staggered so that around each of them, there was a symmetry circle of radius $r_{e}$ (Fig. 4).

Moreover, different parameters such as foil pitch, distance between tubes, foil thickness, tube radius, tube wall temperature were evaluated to analyze the effect of the geometry on heat transfer and discharge time.
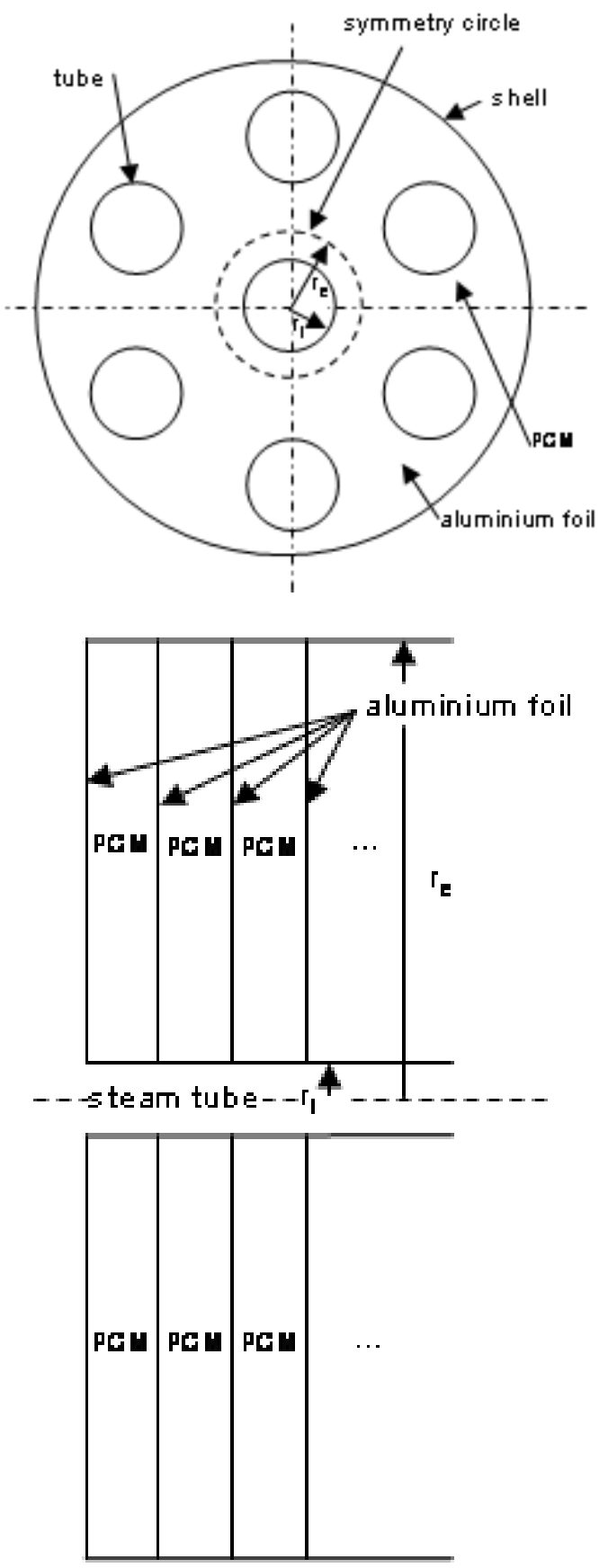

Fig. 4. Schematic of HTLHTES with aluminium foil [8].

New composites made of salts or eutectics and graphite flakes, have been presented as materials whose stability, storage capacity and thermal conductivity are suitable to 
be implanted in LHTS of thermal solar power plants [2, 11, 12].

Pincemina et al. used in their work three different types of industrial graphite to get the thermal conductivity enhancement [2]. In this work the dispersion of graphite flakes in the PCM was used as the elaboration route. This dispersion could be achieved above the melting temperature by mechanical dispersion within the molten PCM or at room temperature by mixing the two powdered components. The results of this work showed that the presence of graphite within the PCM induces small reduction in latent heat (from $5 \%$ to $28 \%$ depending upon the type and size of graphite flakes), no significant change in phase change temperature, but a decrease in phase change temperature variation.

In the work presented by Bayón et al. a latent heat thermal storage prototype was tested under real working conditions with steam produced by a parabolic-trough collector [11]. This prototype contained $\mathrm{KNO}_{3} / \mathrm{NaNO}_{3}$ eutectic mixture as phase change material (PCM) and expanded graphite fins arranged in a "sandwich configuration" (Fig. 5) for improving thermal conductivity.

Other researchers have analyzed the influence of graphite structure over thermal properties of these composites. In their work, Acem et al. proposed a new elaboration method (cold-compression) as alternative to foams infiltration [13]. It consists of cold-compression of a physical mixing of expanded natural graphite particles and salt powder. Two different compression routes were investigated: uni-axial compression and isostatic compression. It was proven that cold-compression is a simple and efficient technique for improving the salt thermal conductivity. For instance, graphite amounts between 15 and $20 \%$ wt lead to apparent thermal conductivities close to $20 \mathrm{~W} / \mathrm{m} / \mathrm{K}$ (20 times greater than the thermal conductivity of the salt). For this reason, the authors demonstrated that this method is an efficient technique for improving thermal conductivity.

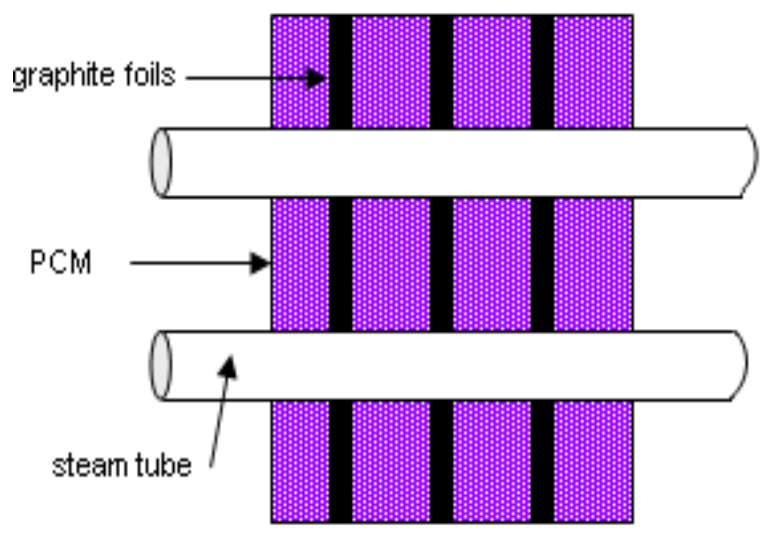

Fig. 5. Scheme of PCM/fins sandwich configuration [11].

Zhao and $\mathrm{Wu}$ evaluated the feasibility of using metal foams and expanded graphite to enhance the heat transfer capability of PCMs in high temperature thermal energy storage systems [14]. Their study focused on composite materials consisting of PCM: $\mathrm{NaNO}_{3}$, metal foams (copper and copper-steel alloy which possess different porosity) and expanded graphite. The experimental results for the melting and freezing processes of $\mathrm{NaNO}_{3}$ with/without metal foams and expanded graphite embedded in cylindrical containers showed that heat transfer can be significantly enhanced by both porous materials (metal foams and expanded graphite). Furthermore, this study analyzed the corrosion problem between $\mathrm{NaNO}_{3}$ and metal foams which could reduce the positive effect of metal foams to improve the thermal performance of PCMs.

These are some of the main alternatives that have been developed to reduce the low thermal conductivity of PCMs as thermal storage system in solar power plants. Nevertheless, these alternatives are still in a research phase.

\section{Conclusion}

There is a strong need to develop new LHTS that facilitate the reduction of cost energy produced by thermal solar power plants. An important possibility is the implementation of PCMs. However, these materials posses a low thermal conductivity, so it is needed a strong research in the development of techniques and systems which could increase the capacity of PCMs to storage solar energy.

Nowadays, the development of efficient LHTS is in a research phase which is showing different potential solutions to implement PCMs in solar power plants. The next target is the implantation of these techniques in pilot scale which make possible the future application in real plants in order to make them more competitive through electricity costs reduction.

\section{References}

[1] F. Cavallaro, "Fuzzy TOPSIS approach for assessing thermal-energy storage in concentrated solar power (CSP) systems", Applied Energy, Vol. 87, pp. 496-503 (2010).

[2] S. Pincemina, R. Olivesa, X. Pya, M. Christ, "Highly conductive composites made of phase change materials and graphite for thermal storage", Solar Energy Materials \& Solar Cells, Vol. 92, pp. 603-613 (2008).

[3] F. Agyenim, N. Hewitt, P. Eames, M. Smyth, "A review of materials, heat transfer and phase change problem formulation for latent heat thermal energy storage systems (LHTESS)", Renewable and Sustainable Energy Reviews, Vol. 14, pp. 615-628 (2010).

[4] X. Py, R. Olives, S. Mauran, "Paraffin/porousgraphite-matrix composite as a high and constant power thermal storage material", International Journal of Heat and Mass Transfer, Vol. 44, pp. 2727-2737 (2001).

[5] A. Hoshi, D.R. Mills, A. Bittar, T.S. Saitoh, "Screening of high melting point phase change materials (PCM) in solar thermal concentrating technology based on CLFR", Solar Energy, Vol. 79, pp. 332-339 (2005).

[6] S. Jegadheeswaran, S.D. Pohekar, "Performance enhancement in latent heat thermal storage system: A review", Renewable and Sustainable Energy Reviews, Vol. 13, pp. 2225-2244 (2010). 
[7] H. Michels, R. Pitz-Paal, "Cascaded latent heat storage for parabolic trough solar power plants", Solar Energy, Vol. 81, pp. 829-837 (2007).

[8] C. Guo, W. Zhang, "Numerical simulation and parametric study on new type of high temperature latent heat thermal energy storage system", Energy Conversion and Management, Vol. 49, pp. 919-927 (2008).

[9] R. Adinberg, D. Zvegilsky, M. Epstein, "Heat transfer efficient thermal energy storage for steam generation", Energy Conversion and Management, Vol. 51, pp. 9-15 (2010).

[10] H. Shabgard, T.L. Bergman, N. Sharifi, A. Faghri, "High temperature latent heat thermal energy storage using heat pipes", International Journal of Heat and Mass Transfer, Vol. 53, pp. 2979-2988 (2010).

[11] R. Bayón, E. Rojas, L. Valenzuela, E. Zarza, J. León, "Analysis of the experimental behaviour of a $100 \mathrm{kWth}$ latent heat storage system for direct steam generation in solar thermal power plants", Applied Thermal Engineering, Vol. 30, pp. 2643-2651 (2010).

[12] V. Morisson, M. Rady, E. Palomo, E. Arquis, "Thermal energy storage systems for electricity production using solar energy direct steam generation technology", Chemical Engineering and Processing, Vol. 47, pp. 499507 (2008).

[13] Z. Acem, J. Lopez, E. Palomo, " $\mathrm{KNO}_{3} / \mathrm{NaNO}_{3}-$ Graphite materials for thermal energy storage at high temperature: PartI,- Elaboration methods and thermal properties“, Applied Thermal Engineering, Vol. 30, pp. 1580-1585 (2010).

[14] C.Y. Zhao, Z.G. Wu, "Heat transfer enhancement of high temperature thermal energy storage using metal foams and expanded graphite", Solar Energy Materials \& Solar Cells, Vol. 95, pp. 636-643 (2011). 